\title{
Myositis Ossificans of the Hip Due to Pyogenic Arthritis Caused by Campylobacter fetus Subspecies fetus
}

\author{
Sho Nishiguchi ${ }^{1}$, Ichiro Sekine ${ }^{1}$, Shun Kuroda ${ }^{1}$, Morihiko Sato ${ }^{2}$ and Izumi Kitagawa ${ }^{1}$
}

\begin{abstract}
A 61-year-old woman was admitted with severe hip pain causing immobility and high serum levels of inflammatory markers. The patient had a medical history of diabetes. She had been scheduled to undergo right hip replacement surgery for the treatment of osteoarthritis associated with gradually progressive pain. On admission, an enhanced abdominal computed tomography scan showed an abnormal increase in synovial fluid surrounding the right ilium, with piriformis muscle calcification. Subsequent blood and specimen cultures identified Campylobacter fetus subspecies fetus. This is a rare report of a case of myositis ossificans followed by $C$. fetus pyogenic arthritis of the hip.
\end{abstract}

Key words: Campylobacter fetus subspecies fetus, myositis ossificans, pyogenic arthritis, hip joint, osteoarthritis

(Intern Med 56: 967-972, 2017)

(DOI: 10.2169/internalmedicine.56.7906)

\section{Introduction}

Myositis ossificans (MO) is a rare and benign boneforming condition of the muscles that may be mistaken, both clinically and histologically, for sarcoma $(1,2)$. In many of the cases in which MO is diagnosed, there is marked dysfunction around the muscles (3). MO usually occurs after trauma in the muscles of the extremities $(4,5)$; patients with an infection-related etiology, including septic arthritis, are rare (6). There are no previously reported cases of MO of the hip due to pyogenic arthritis caused by Campylobacter fetus subspecies fetus. We herein describe a rare case of MO that occurred after $C$. fetus pyogenic arthritis of the hip.

\section{Case Report}

A 61-year-old woman with diabetes mellitus presented with a one-month history of progressive right hip pain. She had been aware of discomfort of the right hip joint for the previous seven months. Her orthopedic surgeon had scheduled right hip surgery for the treatment of osteoarthritis.
However, her pain became intolerable, and she became unable to walk. She was admitted to our hospital to investigate the cause of the right hip arthralgia and her high serum levels of inflammatory markers. There were no symptoms of abdominal pain or diarrhea. She had been diagnosed with hyperglycemia several years previously during a health check, however, she thereafter never again visited a medical facility for any follow-up treatment. The patient denied a history of trauma or excessive alcohol consumption. The patient had two dogs that had no history of diarrhea.

The patient's body temperature was $37.2^{\circ} \mathrm{C}$, her blood pressure was $126 / 76 \mathrm{mmHg}$, and her heart rate was 96 beats per minute. She was obese, with a body mass index of 28.7 $\mathrm{kg} / \mathrm{m}^{2}$. A physical examination revealed tenderness, warmth, and swelling of the right hip; pain upon movement; and a difference in the lengths of the bilateral lower limbs. There were no scars, abdominal tenderness, or any other joint pain.

A laboratory investigation revealed the following findings: white cell count, $19,700 / \mu \mathrm{L}$ with $90 \%$ neutrophilic leukocytes; hemoglobin, $11.2 \mathrm{~g} / \mathrm{dL}$; platelet count, $54.5 \times 10^{4} / \mu \mathrm{L}$; total protein, $6.0 \mathrm{~g} / \mathrm{dL}$; albumin $2.2 \mathrm{~g} / \mathrm{dL}$; creatinine, 0.51 $\mathrm{mg} / \mathrm{dL}$; estimated glomerular filtration rate, $92.0 \mathrm{~mL} / \mathrm{min}, \mathrm{C}$ reactive protein, $35.4 \mathrm{mg} / \mathrm{dL}$, and hemoglobin $\mathrm{A} 1 \mathrm{c}, 6.7 \%$. A

${ }^{1}$ Department of General Internal Medicine, Shonan Kamakura General Hospital, Japan and ${ }^{2}$ Department of Infection Control and Prevention, Shonan Kamakura General Hospital, Japan

Received for publication June 25, 2016; Accepted for publication July 31, 2016

Correspondence to Dr. Sho Nishiguchi, sanazen@hotmail.co.jp 


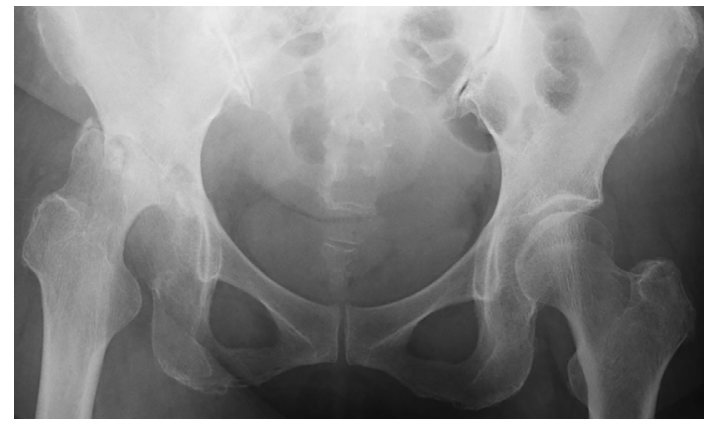

Figure 1. Pelvic X-ray: Bone dislocation.

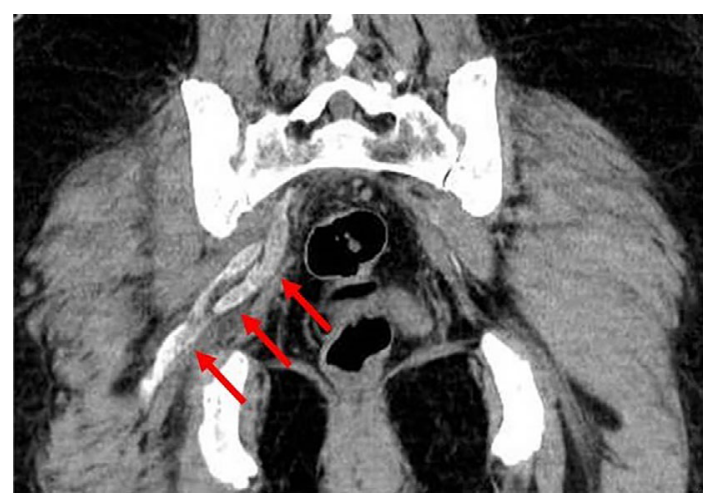

Figure 3. Contrast-enhanced coronal CT s.

urinalysis revealed a few white and red blood cells under high-power fields, and >1 gram-negative rod bacterium, which were suggestive of Escherichia coli. A pelvic X-ray showed destruction of the right hip joint, but no obvious ectopic bone formation around the hip (Fig. 1). Trans-thoracic echocardiography revealed no vegetation and no valve regurgitation. Contrast-enhanced abdominal computed tomography $(\mathrm{CT})$ revealed fluid around the right hip and partial calcification within the surrounding iliopsoas muscle, suggestive of MO (Fig. 2). However, no other abnormal findings (including an aneurysm) were detected. Magnetic resonance imaging (MRI) could not be performed due to the patient's intolerance of severe pain. On admission, the intravenous administration of ceftriaxone (2.0 g/day) and vancomycin (1.5 g/day) was initiated to treat a urinary tract infection caused by gram-negative rods, and for presumptive arthritis of the hip due to a gram-positive coccus. The patient's fever rapidly normalized after the initiation of antibiotic therapy.

The blood cultures yielded gram-negative curved rods on the 4th day after admission. Thus, on the 5th day after admission, a CT-guided right hip joint fluid aspiration was performed to identify the pathogen via culture. A pathological investigation of the calcification was not possible due to the small volume of aspirate that was obtained. Gram staining of the aspirated fluid also revealed gram-negative curved rods. In an external laboratory, the gram-negative curved rods were found to grow on blood agar at $25^{\circ} \mathrm{C}$ and $42^{\circ} \mathrm{C}$, which was suggestive of Campylobacter jejuni, E. coli, or C. fetus. In addition, because of their short length, the gram-

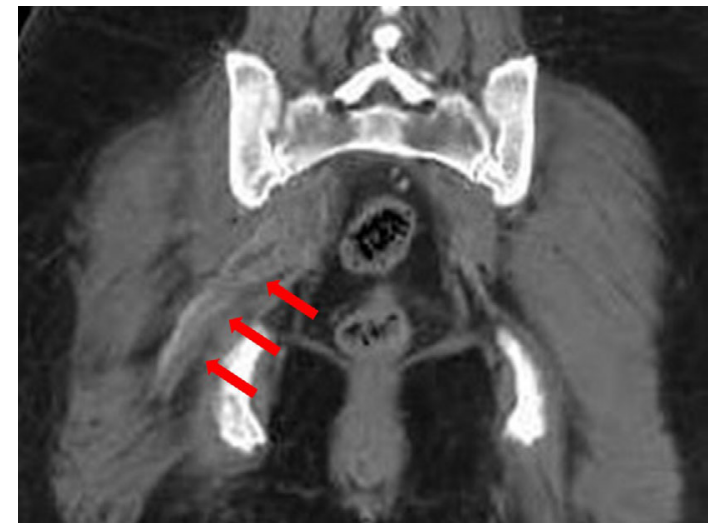

Figure 2. Contrast-enhanced coronal CT s.

negative curved rods from the blood and aspirated fluid cultures were evaluated for C. fetus on the 16th day after admission. Subsequently, the specimen was sent to a university laboratory for a multiplex polymerase chain reaction (PCR), which led to the identification of C. fetus subspecies fetus. An antibiotic sensitivity assay using the disc method showed that the strain was susceptible to ampicillin, ceftriaxone, gentamicin, minocycline, levofloxacin, cefepime, fosfomycin, and imipenem/cilastatin. The antibiotic therapy was switched to intravenous ampicillin ( $8.0 \mathrm{~g} /$ day) according to the sensitivity determination. The patient's pain was partially relieved, but remained during movement. A follow-up enhanced-contrast coronal CT scan on the 11th day after admission revealed that fluid remained around her right hip and expanding calcification involving the right iliopsoas muscle (Fig. 3). MO was finally diagnosed due to deterioration of the borne-forming condition. The patient was transferred to another hospital with an orthopedic surgery department to undergo surgical drainage at three weeks following admission. On the third day after the transfer, right hip debridement was performed and the pus in her hip joint was removed by washing. Intravenous ampicillin treatment for seven weeks and oral amoxicillin therapy were subsequently initiated. Four months after discharge, and soon after switching to oral medication, the patient underwent total hip arthroplasty. However, three weeks after the surgical treatment, she was diagnosed with artificial joint infection, which required an additional two months of antibiotic therapy. Finally, after three surgeries, the patient regained the ability to walk.

\section{Discussion}

In the present case, $C$. fetus pyogenic arthritis developed in a patient with a long history of osteoarthritis who had been scheduled to undergo replacement surgery of the right hip. In addition, the patient showed MO upon admission in the absence of trauma.

MO, which is also known as heterotrophic calcification (7), occurs as a result of muscular trauma. Trauma in young athletes accounts for $75 \%$ of all MO cases $(2,8)$. 
Other possible etiologies include infection, burns, neuromuscular disorders, hemophilia (factor-IX deficiency), and drug abuse (6). The mechanism underlying the development of MO remains unclear. Early in the disease, the lesion is soft and painful and, within a few weeks, a firm and often painful mass develops in the affected muscles. This lesion matures over 12 months, and eventually ossifies and becomes painless. MO is often confused with, and must be distinguished from, sarcoma (7). In $10-20 \%$ of patients, it results in significant functional deficits including the interference of join motion and a limitation in the range of motion (9). Rehabilitation to prevent such deficits is important. MO is a self-limited disease and can resolve spontaneously (10).

The mechanism underlying the development of MO due to infection is unclear; however, it has been suggested that a reactive condition induced by infection may be involved (11). Previous reports have included cases of tetanus and odontogenic infection $(12,13)$. In a report of MO associated with pyogenic arthritis in pediatric patients, there were cases of post-pyogenic arthritis of the hip (14). MO developed in 4 of 39 (10.3\%) patients with pyogenic arthritis of the hip who required surgical treatment (14). As in these cases, infection may be one of the triggers of MO. In the present case, the patient's MO might have been caused by pyogenic arthritis due to C. fetus, which is a rare etiology, since infection is one of the less common nontraumatic causes of MO.

Although MRI has been shown to be useful in the diagnosis of MO, we did not perform MRI of the patient's hip in the present case (15). In a previous study, MRI revealed various characteristics of the lesions at different stages (15). In the early stage, the lesion is typically isointense on T1weighted images and hyperintense on T2-weighted images. Thus, the early stage of MO may mimic an aggressive soft tissue malignant mass, whereas, a hypointense border corresponding to peripheral calcification is observed in the intermediate stage. However, in the late stage, the intensity is decreased due to dense ossification and fibrosis.

Pathological investigation is the gold-standard method for the diagnosis of MO. In the present case, we were unable to perform a pathological analysis of the calcification in the lesion. In a previous study, MO passed through three stages: early, intermediate, and late (16). In the early stage, at 7-10 days, there was a central core of myxoid matrix and fibroblasts, and a minor peripheral osteoid component. In the intermediate stage, the fibroblasts had differentiated into osteoblasts and had begun to secrete an osteoid matrix, initiating from the periphery. Thus, a shell of lamellar bone formed around the lesion and progressed centripetally. In the late stage, mature lamellar bone was observed. It takes 7-8 weeks for a lesion to attain maturity. Following maturation, the lesion may regress in size and. It will spontaneously resolve in approximately $30 \%$ of patients (17). Trauma is recognized as one of the triggers of the pathogenesis of MO. In previous studies, a signal from the site of trauma, such as a bone morphogenetic protein (BMP), may stimulate the mes- enchymal cells to differentiate into chondroblasts or osteoblasts in the early stage of MO $(18,19)$. Based on this finding, it has been hypothesized that infection may induce signaling agents, such as BMP, in the early stages of MO (13). Thus, in the present case, pyogenic arthritis may have had an important role in the pathogenesis of MO.

C. fetus is a relatively rare an infectious agent of humans and its identification is challenging. Campylobacter is a well-known, major cause of gastrointestinal tract infections in humans. C. jejuni, which is the most common species of this genus, accounts for $>88 \%$ of the gastrointestinal infections caused by Campylobacter (20). C. jejuni infections usually occur in previously healthy patients and cause diarrhea. Conversely, C. fetus infections occur in patients with an underlying malignancy or diabetes, or those receiving immunosuppressive treatment $(21,22)$. Furthermore, C. fetus infections rarely cause diarrhea, but are associated with systemic symptoms, including fever, chills, and myalgia, which are symptoms of bacteremia (23-25). In addition, C. jejuni infections are usually self-limited and occur in healthy patients, whereas $C$. fetus infections may be fatal in patients who are immunocompromised or elderly (26). The isolation of C. fetus from clinical specimens is difficult and generally takes $>72$ hours due to its inability to metabolize glucose and its slow growth rate (27-29). C. fetus usually grows at $25-37^{\circ} \mathrm{C}$; however, numerous laboratories routinely incubate at $42^{\circ} \mathrm{C}$. Thus, in standard laboratories, the incubation temperature should be modified from the routine temperature in order to detect C. fetus (30). C. fetus is divided into three subspecies: C. fetus subsp. fetus, C. fetus subsp. venerealis, and C. fetus subsp. testudinum subsp. nov (31). Bacteriological strain typing methods involving pathogen culturing, such as the API-CAMPY Identification Kit from bioMérieux, are available as a diagnostic tool for the differentiation of the subtypes; however, reliable subspecies identification requires a multiplex PCR using a $16 \mathrm{~S}$ rRNA-PCR, which may be completed within several hours and which is as an alternative to bacteriological strain typing (32-35). C. fetus. subsp. fetus has been isolated from wild and domestic cattle, sheep, goats, pigs, cats, and fowl $(21,36,37)$. These animals are considered to be a source of the infections that are caused by this organism (38). Thus, patients with an underlying malignancy or diabetes, or those receiving immunosuppressive treatment, should avoid contact with these animals.

C. fetus is a rare cause of soft tissue, bone, and joint infections (39); C. fetus pyogenic arthritis is especially rare. It is well-known that $C$. fetus causes bacteremia; however, there are few reports of septic arthritis caused by $C$. fetus in which C. fetus was isolated from blood cultures (40-42). The cases in which $C$. fetus arthritis was diagnosed using isolates obtained by arthrocentesis are listed in Table $(38,40-47)$. The average age of the patients was 70 years and 6 of the patients $(55 \%)$ were men. The countries and/or regions in which the cases were reported are as follows: the United States, n=4; France, $n=2$; Asia, n=2; Canada, $\mathrm{n}=1$; the United Kingdom, $\mathrm{n}=1$; and New Zealand, $\mathrm{n}=1$. 


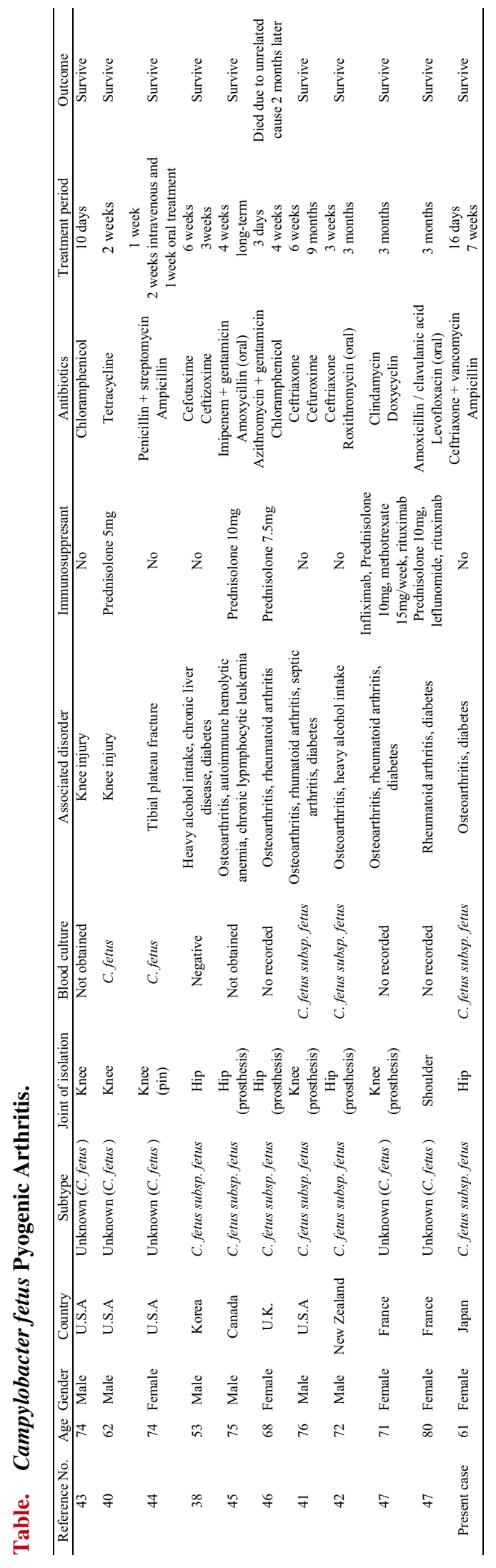

A total of 6 patients (55\%) had C. fetus subsp. fetus, and 5 patients $(45 \%)$ had an unknown subtype. Among the patients in whom a joint location of $C$. fetus was determined, 5 $(45 \%)$ cases involved the knee, 5 (45\%) involved the hip, and $1(9 \%)$ involved the shoulder. Among the 5 patients with knee arthritis, $3(60 \%)$ were associated with a prosthetic joint infection and $2(40 \%)$ with a native joint infection. In addition, among the 5 patients with hip arthritis, 3 $(60 \%)$ were associated with a prosthetic joint infection and $2(40 \%)$ with a native joint infection. A total of 5 patients (45\%) developed systemic bacteremia due to C. fetus. An analysis of the underlying disorders associated with the bone or joint showed that 6 patients $(55 \%)$ had osteoarthritis, 4 (35\%) had rheumatoid arthritis, $3(27 \%)$ had a bone injury or fracture, and 1 patient $(9 \%)$ had no obvious bone or joint disorder. In addition, 5 patients $(45 \%)$ had diabetes and 2 (17\%) had a history of alcohol abuse. Five patients (45\%) were treated with immunosuppressants. Furthermore, half of the patients received inconsistent intravenous penicillin or cephem antibiotics and almost all of the patients required intravenous antibiotic treatment for at least 2 weeks, with the exception of 1 patient whose infection lasted for 10 days (43).

The optimum combination of antibiotics and duration of treatment for $C$. fetus infections have yet to be established. Intravenous ampicillin is known to lead to a good outcome in patients with $C$. fetus infections. If a $C$. fetus infection leads to an endovascular infection, at least four weeks of antibiotic treatment with ampicillin or gentamicin may be required (48). Imipenem or meropenem are good alternatives, but should be switched to narrow spectrum antibiotics following an antibiotic sensitivity assay to prevent the development of resistant bacteria (49). In this case, the patient was treated with intravenous ampicillin for seven weeks, followed by oral amoxicillin therapy for $C$. fetus pyogenic arthritis. Ampicillin, which is a narrow-spectrum bactericidal intravenous antibiotic, was selected based on a sensitivity assay, and also because the use of broad-spectrum antibiotics for long periods has been shown to promote the development of resistant bacteria.

If the condition of a patient with pyogenic arthritis does not improve after an appropriate antibiotic regime, immediate surgical drainage is essential (14). In the present case, the patient with a long history of osteoarthritis presented with severe hip pain, which was initially attributed to the worsening of her osteoarthritis. Pyogenic arthritis and subsequent $\mathrm{MO}$ are associated with a high risk of joint disability $(6,9)$; thus, an early diagnosis and drainage were required to reduce the significant morbidity associated with MO.

In conclusion, MO is a rare and benign condition that is typically caused by muscular trauma but which may infrequently occur in patients who have not experienced trauma due to the presence of an infection, such as pyogenic arthritis. In addition, $C$. fetus may be a rare cause of pyogenic arthritis in patients who are immunocompromised or who have 
a history of close animal contact. In order to prevent the impaired mobility of the joint due to subsequent MO, physicians should be vigilant when treating pyogenic arthritis in immunocompromised patients who present with severe joint pain.

The authors state that they have no Conflict of Interest (COI).

\section{Acknowledgement}

The authors would like to thank Dr. Toshiki Tsukiyama for editing the images and Dr. Kiyofumi Okusu who performed the PCR which identified the pathogen.

\section{References}

1. Kamalapur MG, Patil PB, Joshi S, Shastri D. Pseudomalignant myositis ossificans involving multiple masticatory muscles: Imaging evaluation. Indian J Radiol Imaging 24: 75-79, 2014.

2. Lacout A, Jarraya M, Marcy PY, Thariat J, Carlier RY, et al. Myositis ossificans imaging: keys to successful diagnosis. Indian J Radiol Imaging 22: 35-39, 2012.

3. King JB. Post-traumatic ectopic calcification in the muscles of athletes: a review. Br J Sports Med 32: 287-290, 1998.

4. Tsuno MM, Shu GJ. Myositis ossificans. J Manipulative Physiol Ther 13: 340-342, 1990.

5. Wiggins RL, Thurber D, Abramovitch K, Bouquot J, Vigneswaran N. Myositis ossificans circumscripta of the buccinator muscle: first report of a rare complication of mandibular third molar extraction. J Oral Maxillofac Surg 66: 1959-1963, 2008.

6. El Bardouni A, Boufettal M, Zouaidia F, et al. Non-traumatic myositis ossificans circumscripta: a diagnosis trap. J Clin Orthop Trauma 5: 261-265, 2014.

7. Hendifar AE, Johnson D, Arkfeld DG. Myositis ossificans: a case report. Arthritis Rheumatism 53: 793-795, 2005.

8. Defoort S, Arnout NA, Debeer PD. Myositis ossificans circumscripta of the triseps due to overuse in a female swimmer. Int $\mathrm{J}$ Shoulder Surg 6: 19-22, 2012.

9. Rothwell AG. Quadriceps hematoma. A prospective clinical study. Clin Orthop Relat Res 171: 97-103, 1982.

10. Beiner JM, Jokl P. Muscle contusion injury and myositis ossificans traumatica. Clin Orthop Relat Res 403S Suppl: S110-S119, 2002.

11. Angervall L, Stener B, Stener I, Ahren C. Pseudomalignant osseous tumour of soft tissue. A clinical, radiological and pathological study of five cases. J Bone Joint Surg Br Volume 51: 654-663, 1969.

12. Pitts NC. Myositis ossificans as a complication of tetanus. JAMA 189: 237-239, 1964.

13. Jiang Q, Chen MJ, Yang C, et al. Post-infectious myositis ossificans in medial, lateral pterygoid muscles: A case report and review of the literature. Oncol Lett 9: 920-926, 2015.

14. Umer M, Hashmi P, Ahmad T, Ahmed M, Umar M. Septic arthritis of the hip in children: Aga Khan University Hospital experience in Pakistan. J Pak Med Assoc 53: 472-478, 2003.

15. Kransdorf MJ, Meis JM, Jelinek JS. Myositis ossificans: MR appearance with radiologic-pathologic correlation. AJR Am J Roentgenol 157: 1243-1248, 1991.

16. Baysal T, Baysal O, Sarac K, Elmali N, Kutlu R, Ersoy Y. Cervical myositis ossificans traumatica: a rare location. European radiology 9: 662-664, 1999.

17. Ogilvie-Harris DJ, Fornasier VL. Pseudomalignant myositis ossificans: heterotopic new-bone formation without a history of trauma. J Bone Joint Surg Am 62: 1274-1283, 1980.

18. Yu PB, Deng DY, Lai CS, et al. BMP type I receptor inhibition reduces heterotopic [corrected] ossification. Nat Med 14: 13631369,2008
19. Katagiri T. BMP signaling and bone formation. Clinical Calcium 22: 1677-1683, 2012 (in Japanese).

20. Centers for Disease Control and Prevention. Foodborne Diseases Active Surveillance Network (FoodNet): FoodNet Surveillance Report for 2011 (Final Report). Atlanta: U.S. Department of Health and Human Services, 2012.

21. Francioli P, Herzstein J, Grob JP, Vallotton JJ, Mombelli G, Glauser MP. Campylobacter fetus subspecies fetus bacteremia. Arch Intern Med 145: 289-292, 1985.

22. Pigrau C, Bartolome R, Almirante B, Planes AM, Gavalda J, Pahissa A. Bacteremia due to Campylobacter species: clinical findings and antimicrobial susceptibility patterns. Clin Infect Dis 25: 1414-1420, 1997.

23. Guerrant RL, Lahita RG, Winn WC Jr, Roberts RB. Campylobacteriosis in man: pathogenic mechanisms and review of 91 bloodstream infections. Am J Med 65: 584-592, 1978.

24. Franklin B, Ulmer DD. Human infection with vibrio fetus. West $\mathbf{J}$ Med 120: 200-204, 1974.

25. Gazaigne L, Legrand P, Renaud B, et al. Campylobacter fetus bloodstream infection: risk factors and clinical features. Eur J Clin Microbiol Infect Dis 27: 185-189, 2008.

26. Pacanowski J, Lalande V, Lacombe K, et al. Campylobacter bacteremia: clinical features and factors associated with fatal outcome. Clin Infect Dis 47: 790-796, 2008.

27. Tenover FC, Gebhart CJ. Isolation and identification of Campylobacter species. Clin Microbiol Newsl 10: 81-85, 1988.

28. Kiggins EM, Plastridge WN. Some metabolic activities of Vibrio fetus of bovine origin. J Bacteriol 75: 205-208, 1958.

29. Wang WL, Blaser MJ. Detection of pathogenic Campylobacter species in blood culture systems. J Clin Microbiol 23: 709-714, 1986.

30. Allos BM, Blaser MJ. Campylobacter jejuni and Related Species. In: Principles and Practice of Infectious Disease. 7th ed. Mandell GL, Bennett JE, Dolin R, Eds. Churchill Livingstone, Philadelphia, , 2014: 2793-2802.

31. Patrick ME, Gilbert MJ, Blaser MJ, Tauxe RV, Wagenaar JA, Fitzgerald C. Human infections with new subspecies of Campylobacter fetus. Emerg Infect Dis 19: 1678-1680, 2013.

32. Veron M, Chatelain R. Taxonomic study of the genus campylobacter sebald and veron and designation of the neotype strain for the type species, campylobacter fetus (Smith and Taylor) Sebald and Veron. Int J Syst Bacteriol 23: 122-134, 1973.

33. Watine J, Martorell J, Bruna T, Gineston JL, Poirier JL, Lamblin G. In vivo pefloxacin-resistant Campylobacter fetus responsible for gastro-intestinal infection and bacteremia associated with arthritis of the hip. Yonsei Med J 36: 202-205, 1995.

34. Iraola G, Hernández M, Calleros L, et al. Application of a multiplex PCR assay for Campylobacter fetus detection and subspecies differentiation in uncultured samples of aborted bovine fetuses. J Vet Sci 13: 371-376, 2012.

35. Wang G, Clark CG, Taylor TM, et al. Colony multiplex PCR assay for identification and differentiation of Campylobacter jejuni, C. coli, C. lari, C. upsaliensis, and C. fetus subsp. fetus. J Clin Microbiol 40: 4744-4747, 2002.

36. Smibert RM. Genus Campylobacter. In: Bergey's Manual of Systematic Bacteriology. Kreig NR, Holt HG, Eds. Williams \& Wilkins, Baltimore, 1984: 111-118.

37. Fujihara N, Takakura S, Saito T, Iinuma Y, Ichiyama S. A case of perinatal sepsis by Campylobacter fetus subsp. fetus infection successfully treated with carbapenem: case report and literature review. J Infect 53: e199-e202, 2006.

38. Han CD, Lee JW, Chong Y. Pyogenic arthritis of the hip due to Campylobacter fetus: a case report. Yonsei Med J 33: 87-90, 1992.

39. Rollot K, Albert JD, Werner S, et al. Campylobacter fetus septic arthritis revealing a malignancy. Joint Bone Spine 71: 63-65, 2004. 
40. Kilo C, Hagemann PO, Marzi J. Septic arthritis and bacteremia due to vibrio fetus: report of an unusual case and review of the literature. Am J Med 38: 962-971, 1965.

41. Cone LA, Dreisbach PB, Hirschberg J, Shekar C, Dreisbach LP, Salatich W. Cellulitis and septic arthritis caused by Campylobacter fetus and Campylobacter jejuni. J Clin Rheumatol 9: 362-369, 2003.

42. Chambers ST, Morpeth SC, Laird HM. Campylobacter fetus prosthetic hip joint infection: successful management with device retention and review. J Infect 50: 258-261, 2005.

43. King S, Bronsky D. Vibrio fetus isolated from a patient with localized septic arthritis. JAMA 175: 1045-1048, 1961.

44. Kutner LJ, Arnold WD. Septic arthritis due to Vibrio fetus. Report of a case. J Bone Joint Surg Am 52: 161-164, 1970.

45. Yao JD, Ng HM, Campbell I. Prosthetic hip joint infection due to Campylobacter fetus. J Clin Microbiol 31: 3323-3324, 1993.
46. Bates CJ, Clarke TC, Spencer RC. Prosthetic hip joint infection due to Campylobacter fetus. J Clin Microbiol 32: 2037, 1994.

47. Meyer A, Theulin A, Chatelus E, et al. Campylobacter fetus infection in three rheumatoid arthritis patients treated with rituximab. Ann Rheum Dis 71: 1094-1095, 2012.

48. Tremblay C, Gaudreau C, Lorange M. Epidemiology and antimicrobial susceptibilities of 111 Campylobacter fetus subsp. fetus strains isolated in Quebec, Canada, from 1983 to 2000. J Clin Microbiol 41: 463-466, 2003.

49. Neuzil KM, Wang E, Haas DW, Blaser MJ. Persistence of Campylobacter fetus bacteremia associated with absence of opsonizing antibodies. J Clin Microbiol 32: 1718-1720, 1994.

The Internal Medicine is an Open Access article distributed under the Creative Commons Attribution-NonCommercial-NoDerivatives 4.0 International License. To view the details of this license, please visit (https://creativecommons.org/licenses/ by-nc-nd/4.0/).

(C) 2017 The Japanese Society of Internal Medicine http://www.naika.or.jp/imonline/index.html 